J. Venom. Anim. Toxins incl. Trop. Dis.

V.11, n.1, p.1-2, 2005.

Editor's viewpoint - ISSN 1678-9199.

\title{
CEVAP - PRESENT, PAST AND FUTURE
}

The Center for the Study of Venoms and Venomous Animals of UNESP - CEVAP - was founded in 1989 owing to the need of some researchers in obtaining venoms for their studies. Thus, a Complementary Unit of Unesp was constituted, being composed of specialists from the Botucatu School of Medicine, Botucatu Institute of Biosciences, Botucatu School of Veterinary Medicine and Animal Husbandry, Araraquara School of Pharmaceutical Sciences, and Rio Claro Institute of Biosciences.

In 1994, the first scientific electronic journal in Brazil was created: The Journal of Venomous Animals and Toxins; today entitled The Journal of Venomous Animals and Toxins including Tropical Diseases. It is written in English and was initially distributed in diskettes to 68 countries. Since 1997, it has been the only journal from UNESP to be part of the SciELO website, the first scientific electronic library online in Brazil. Until today, about 70,000 people have accessed JVATiTD articles; and 102 Original papers, 23 Review articles, 18 Short communications, 6 Case reports, 80 Theses, and 715 Abstracts from congresses, scientific meetings and symposiums have been published so far. Since 2003, the journal has its own website at www.jvat.org.br . It is classified as Qualis A by Capes in the following areas: Medicine I, Medicine II, Pharmacy, Animal Science, Veterinary Medicine, and Agrarian Sciences. Among the countries that access its website, the United States is the leader in number of visits $(75.75 \%)$, followed by Brazil (18.17\%) and other countries. In 2004, CEVAP also started to edit the Science in Extension Journal (Revista Ciência em Extensão), an official publication of the ProRectory of University Extension from UNESP.

Hundreds of scientific papers were published in the research line of CEVAP, including 10 master's dissertations, $11 \mathrm{PhD}$ theses and 1 postdoctoral thesis.

CEVAP has also produced different teaching materials. In 1994, it launched the first book "Venoms - Clinical and Therapeutic Aspects of Envenoming", and soon two other books with accompanying CDs were published: "Clinical Study of Ophidic Accidents" and "Arthropods of Medical Interest". CEVAP also produced a video library and a DVD 
S. R. C. S. Barraviera. CEVAP - PRESENT, PAST AND FUTURE. J. Venom. Anim. Toxins incl. Trop. Dis., 2005, 11, 1, p. 2.

library on Toxinology, consisted of 20 main themes about venoms and distributed to several faculties all over the country. It offers courses to undergraduate students of Medicine and Nursing (Botucatu School of Medicine and Nursing), Veterinary Medicine (Botucatu, Jaboticabal, and Araçatuba) Biology (Botucatu Institute of Bioscience), and Agronomy (Botucatu School of Agronomical Sciences), besides curricular and extracurricular apprenticeships to students all over Brazil. The Center also provides specialization courses to Brazilians and foreigners.

Nowadays, the teaching philosophy has been focused on long-distance courses, permitting that students or health professionals recycle their knowledge, without leaving their daily activities. So far, 140 Brazilians and 10 foreigners took our course. In addition, CEVAP maintains virtual classrooms, as well as virtual meeting rooms, facilitating the interaction between the teacher and the students through video conferences.

With regard to assistance and extension, CEVAP frequently organizes courses and didactic expositions to high schools, enterprises, and the general population. Today, the Center features a virtual outpatient's department, permitting any person to solve doubts on the most frequent accidents with venomous animals and on the ideal proceedings for each case.

There are approximately 150 Bothrops, 600 Crotalus, and 50 snakes of the other genera available at CEVAP. In this context, it maintains teaching, research, and extension activities.

Now, after almost 15 years, we are moving to our definite building at the Lageado Farm of the Botucatu School of Agronomical Sciences. It is an ambitious project subdivided into an area for public visit, rooms for didactic exposition, laboratories, and an area especially dedicated to the long-distance teaching (Figures).

Silvia Regina C. Sartori Barraviera, MD, PhD.

Director of CEVAP - www. cevap.org.br

srbarraviera@cevap.org.br 
S. R. C. S. Barraviera. CEVAP - PRESENT, PAST AND FUTURE. J. Venom. Anim. Toxins incl. Trop. Dis., 2005, 11, 1, p. 2.

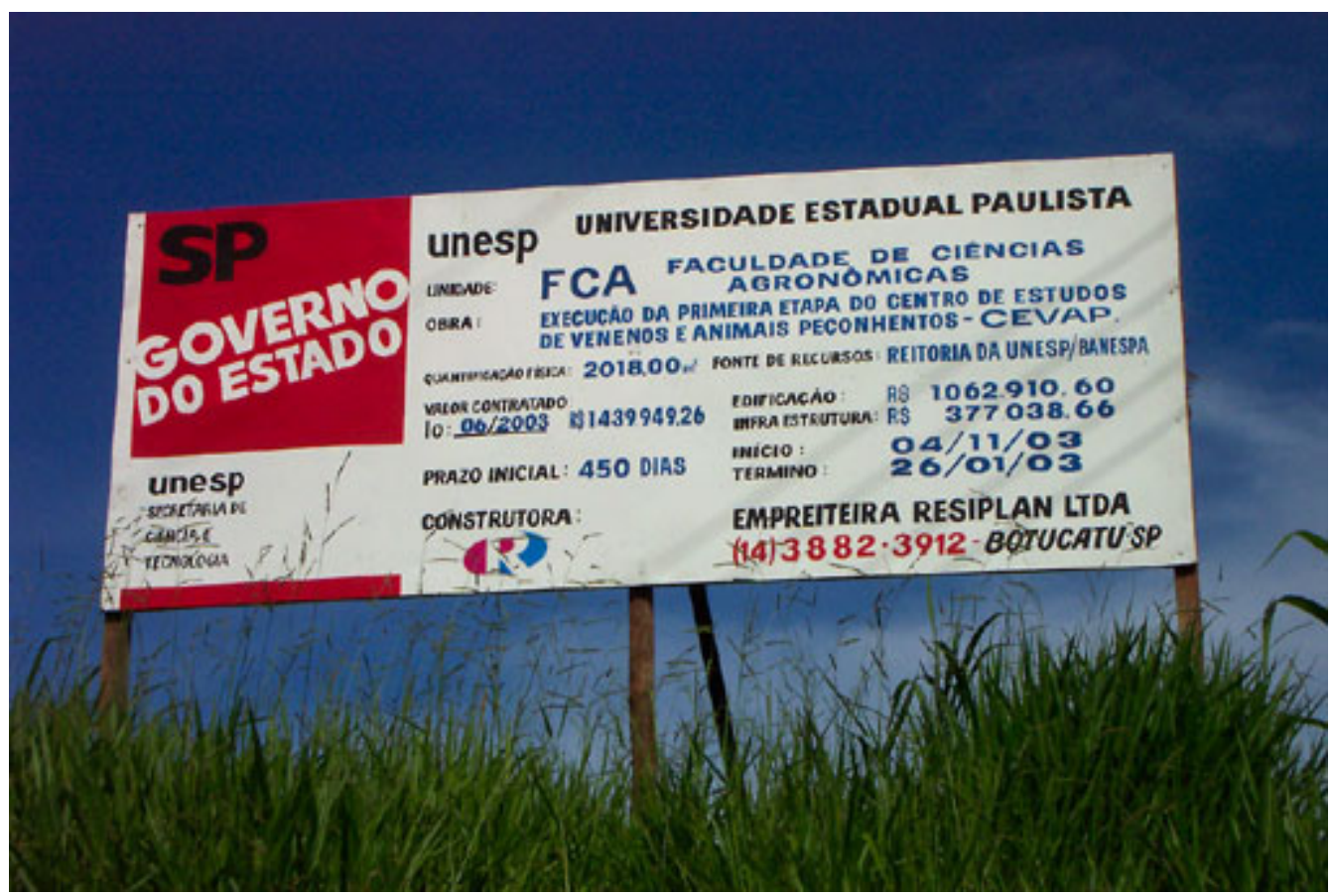


S. R. C. S. Barraviera. CEVAP - PRESENT, PAST AND FUTURE. J. Venom. Anim. Toxins incl. Trop. Dis., 2005, 11, 1, p. 2.

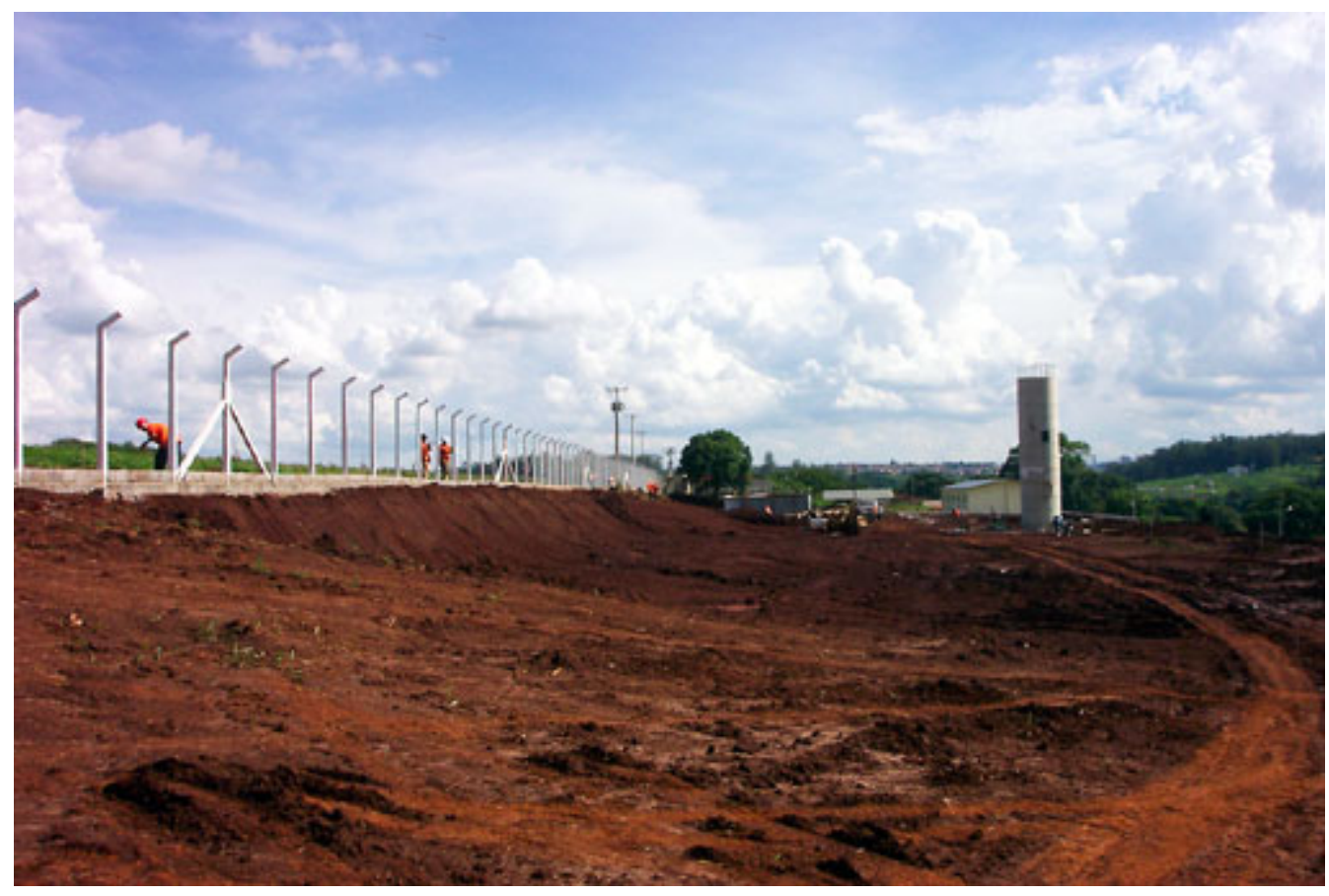


S. R. C. S. Barraviera. CEVAP - PRESENT, PAST AND FUTURE. J. Venom. Anim. Toxins incl. Trop. Dis., 2005, 11, 1, p. 2.

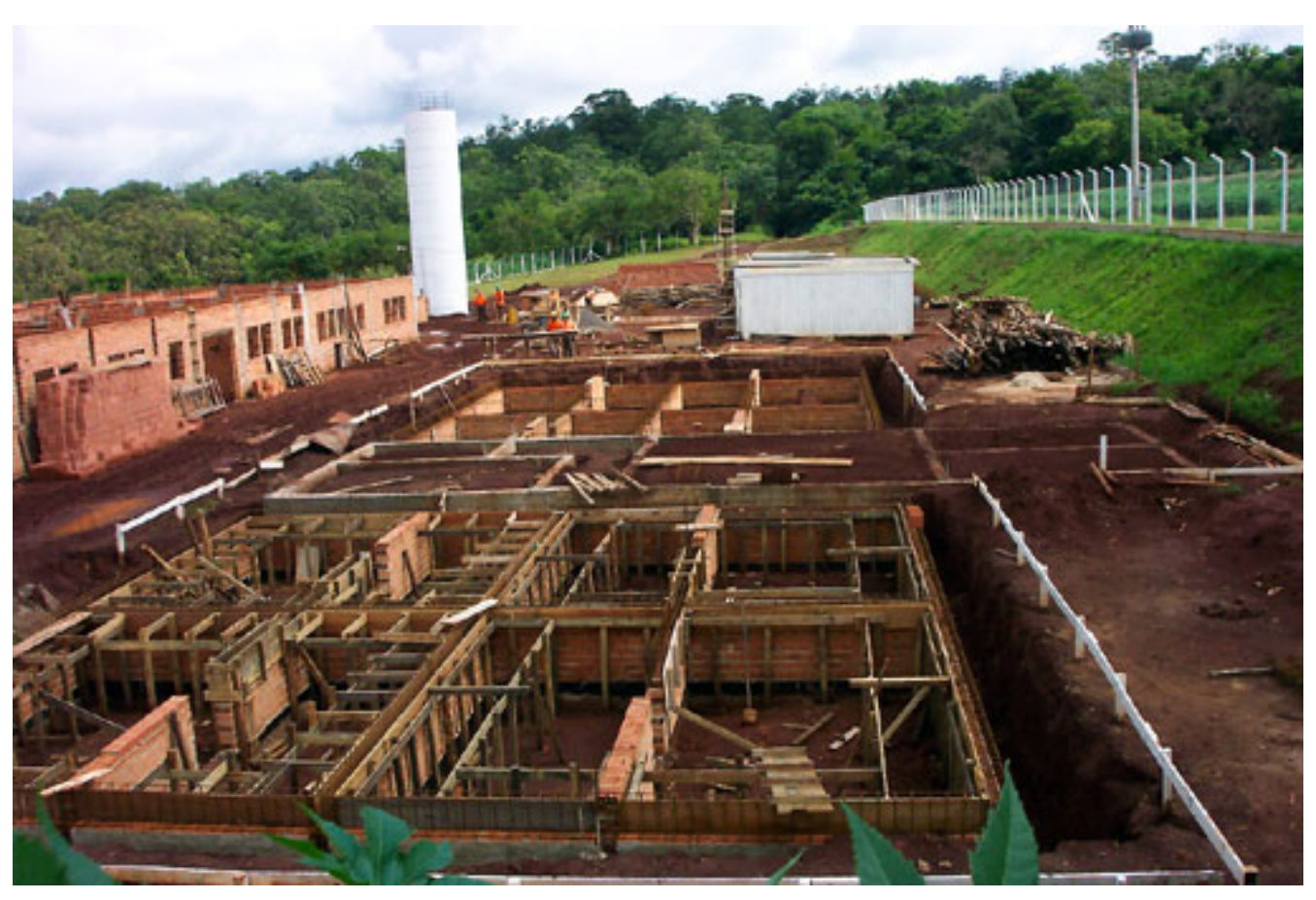


S. R. C. S. Barraviera. CEVAP - PRESENT, PAST AND FUTURE. J. Venom. Anim. Toxins incl. Trop. Dis., 2005, 11, 1, p. 2.

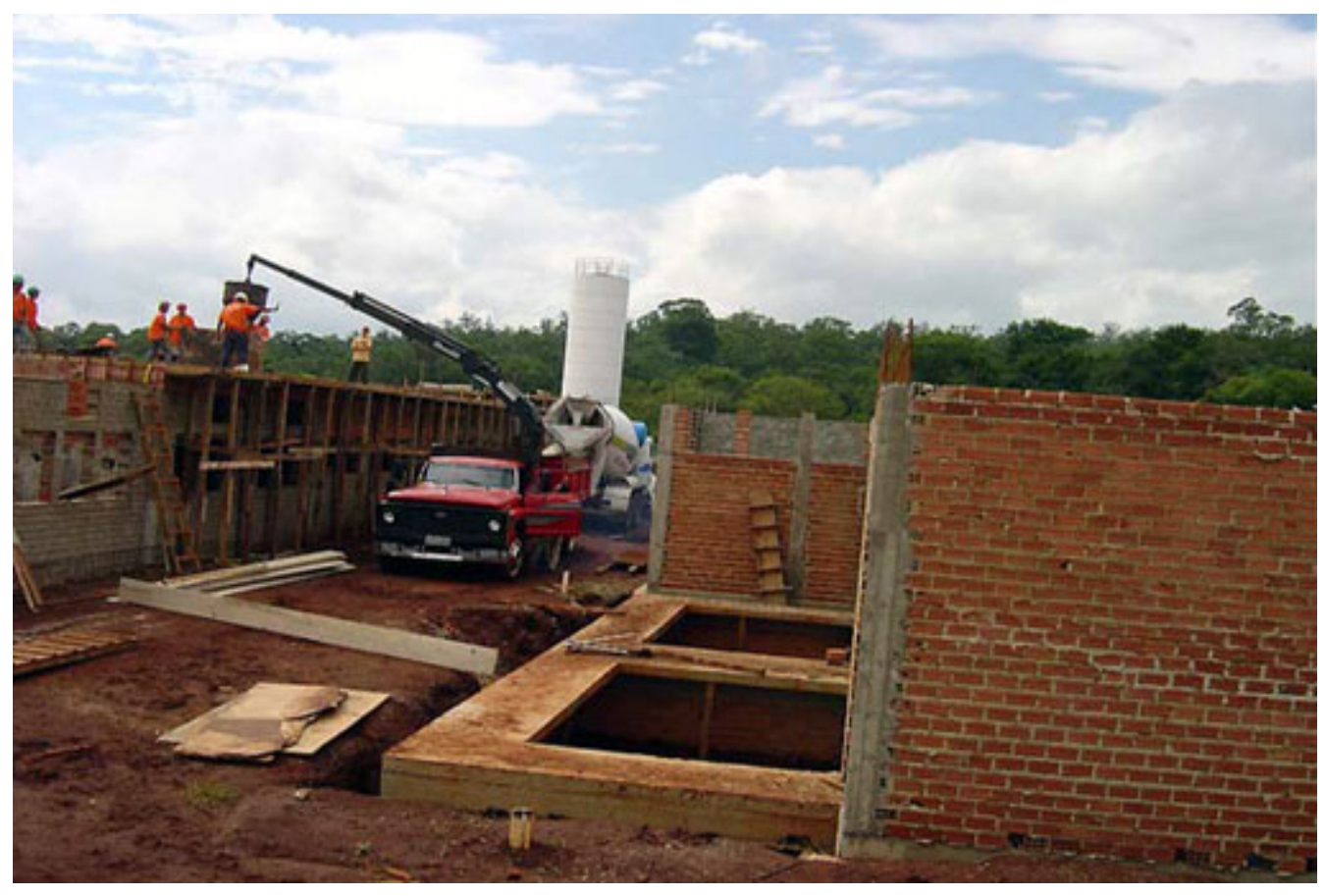


S. R. C. S. Barraviera. CEVAP - PRESENT, PAST AND FUTURE. J. Venom. Anim. Toxins incl. Trop. Dis., 2005, 11, 1, p. 2.

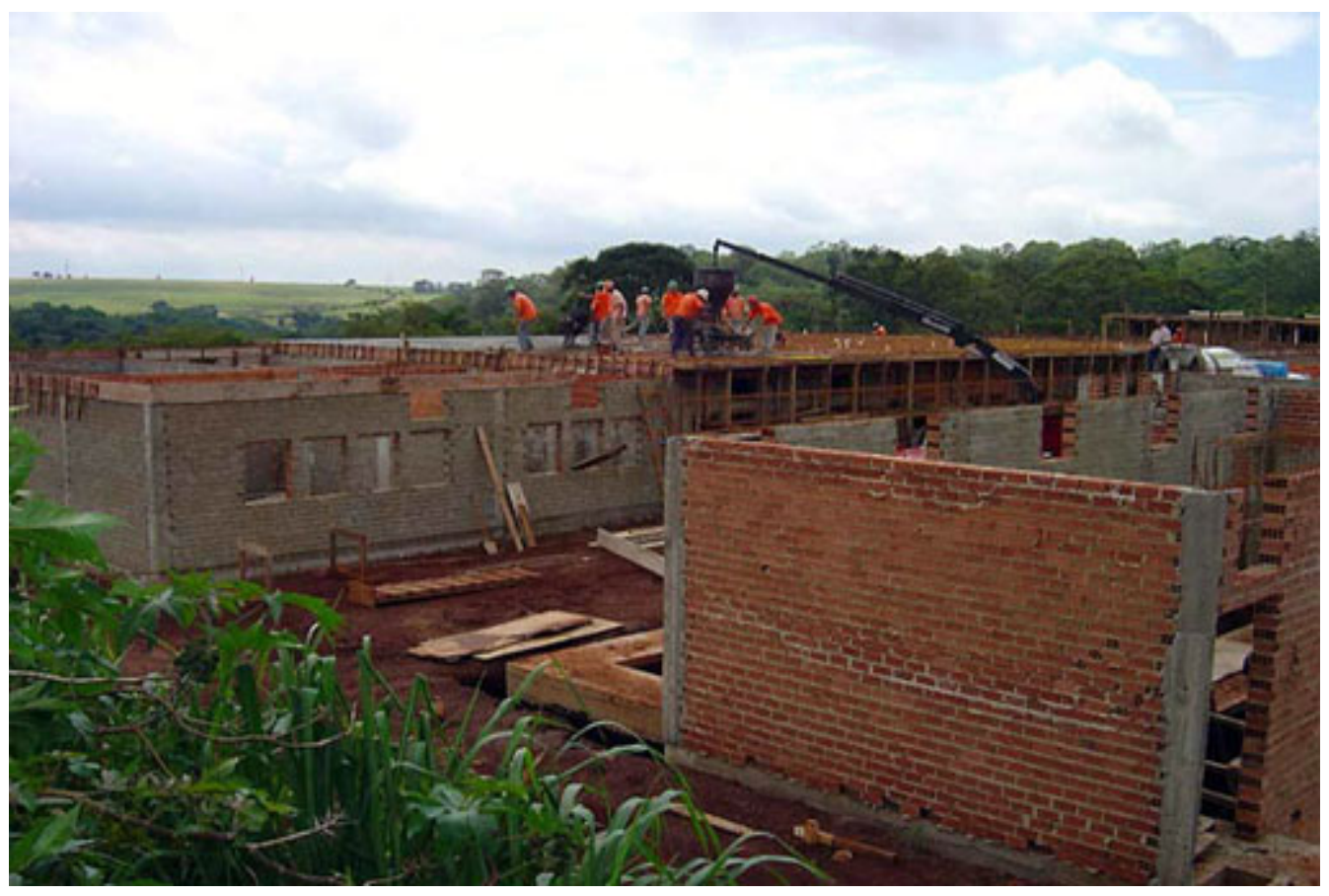


S. R. C. S. Barraviera. CEVAP - PRESENT, PAST AND FUTURE. J. Venom. Anim. Toxins incl. Trop. Dis., 2005, 11, 1, p. 2.

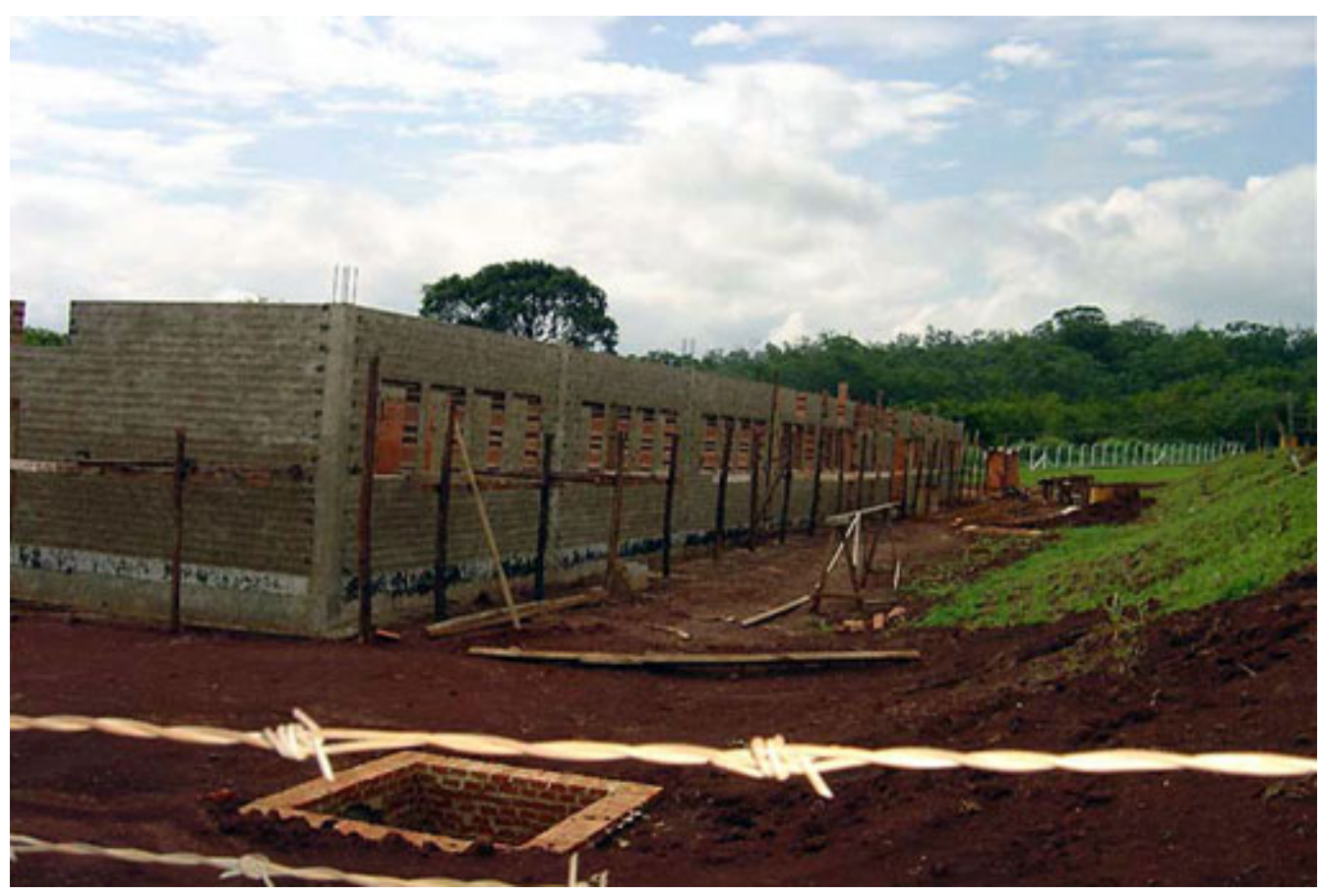


S. R. C. S. Barraviera. CEVAP - PRESENT, PAST AND FUTURE. J. Venom. Anim. Toxins incl. Trop. Dis., 2005, 11, 1, p. 2.

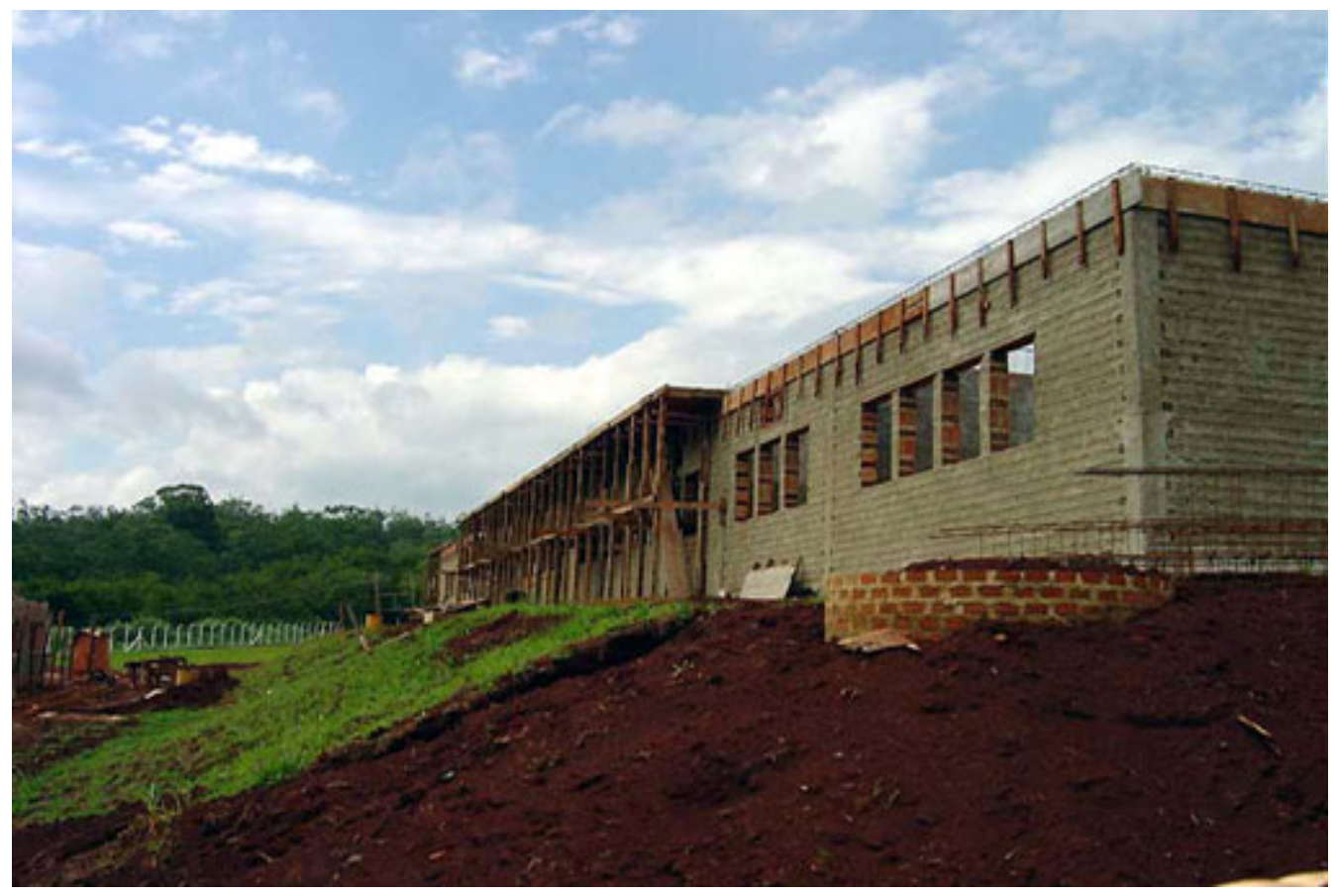


S. R. C. S. Barraviera. CEVAP - PRESENT, PAST AND FUTURE. J. Venom. Anim. Toxins incl. Trop. Dis., 2005, 11, 1, p. 2.

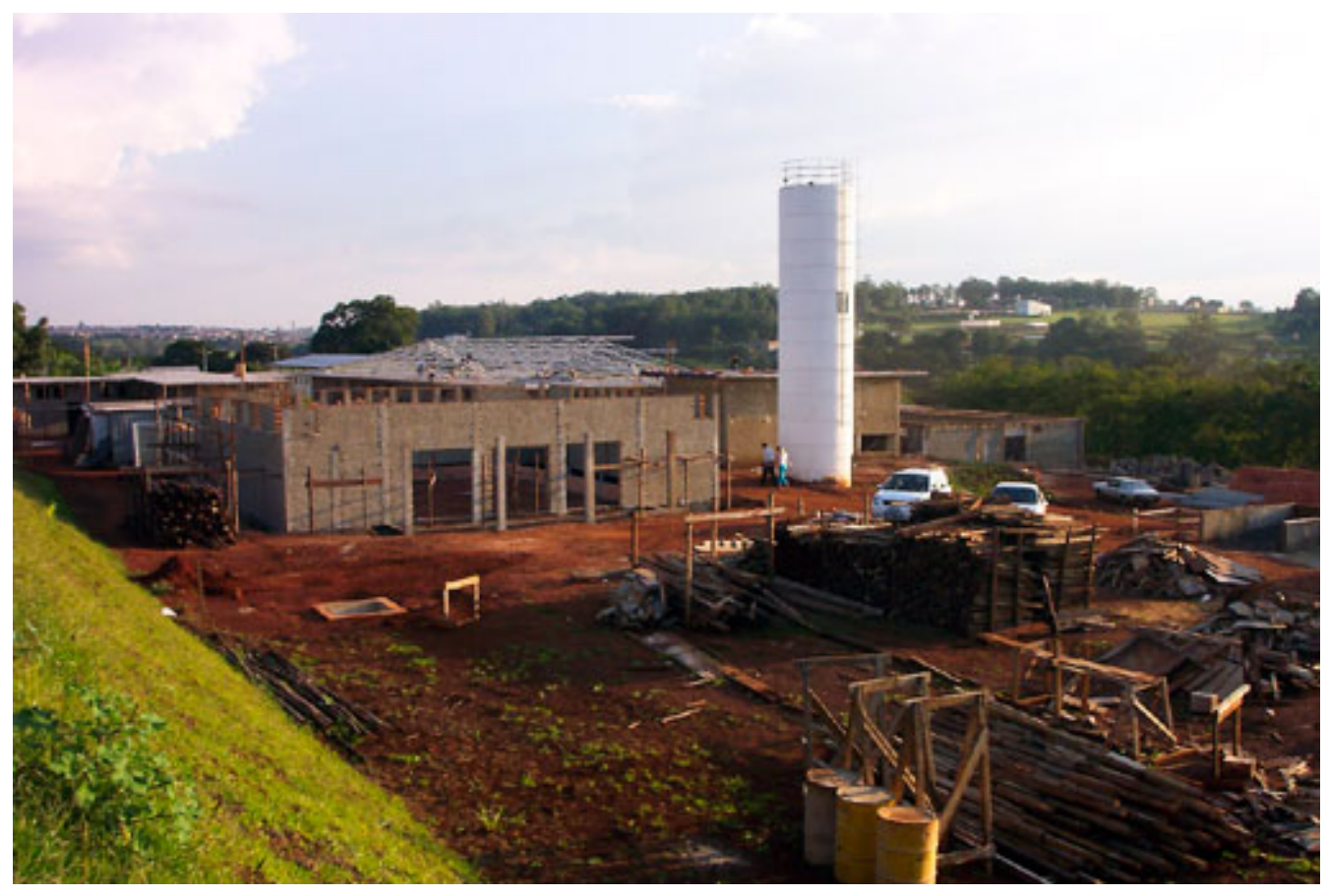


S. R. C. S. Barraviera. CEVAP - PRESENT, PAST AND FUTURE. J. Venom. Anim. Toxins incl. Trop. Dis., 2005, 11, 1, p. 2.

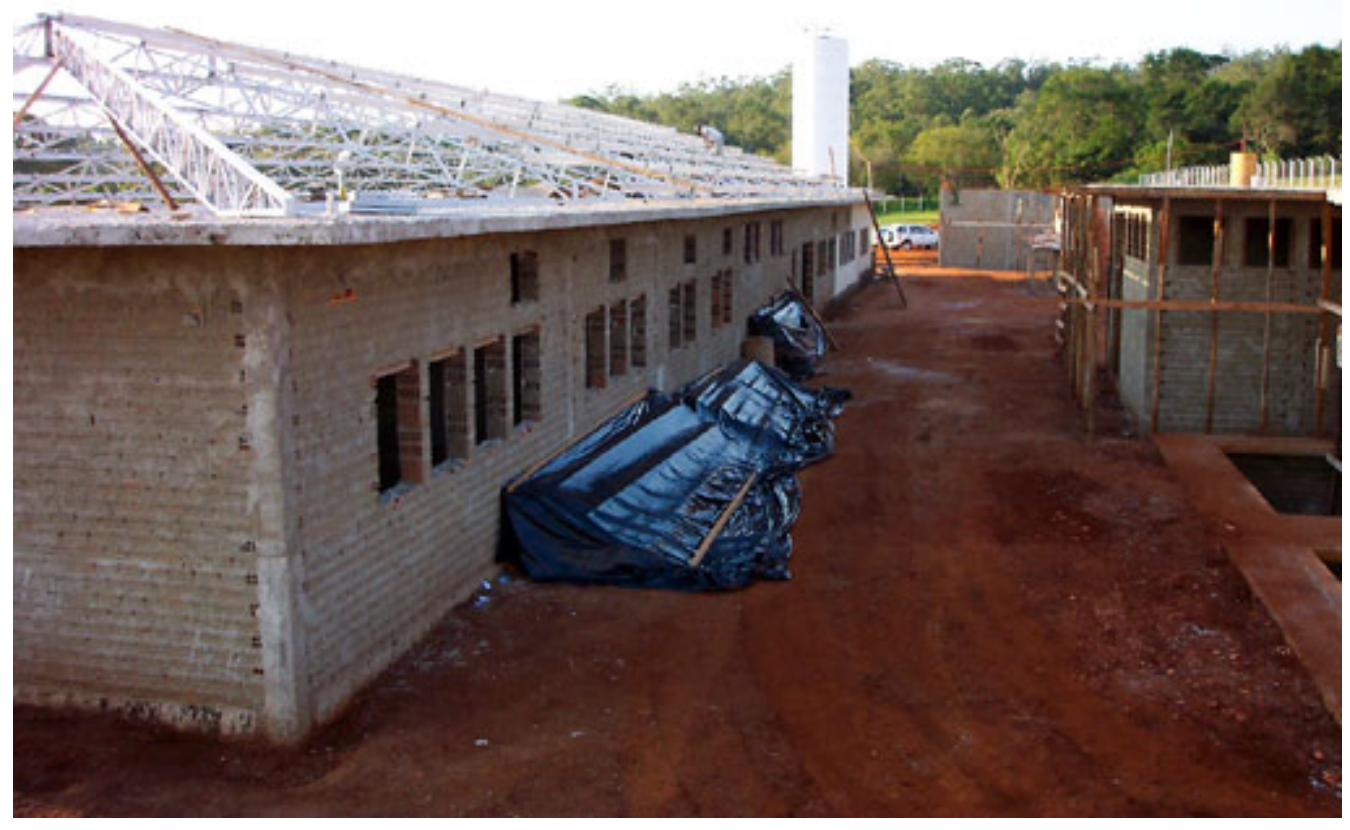


S. R. C. S. Barraviera. CEVAP - PRESENT, PAST AND FUTURE. J. Venom. Anim. Toxins incl. Trop. Dis., 2005, 11, 1, p. 2.

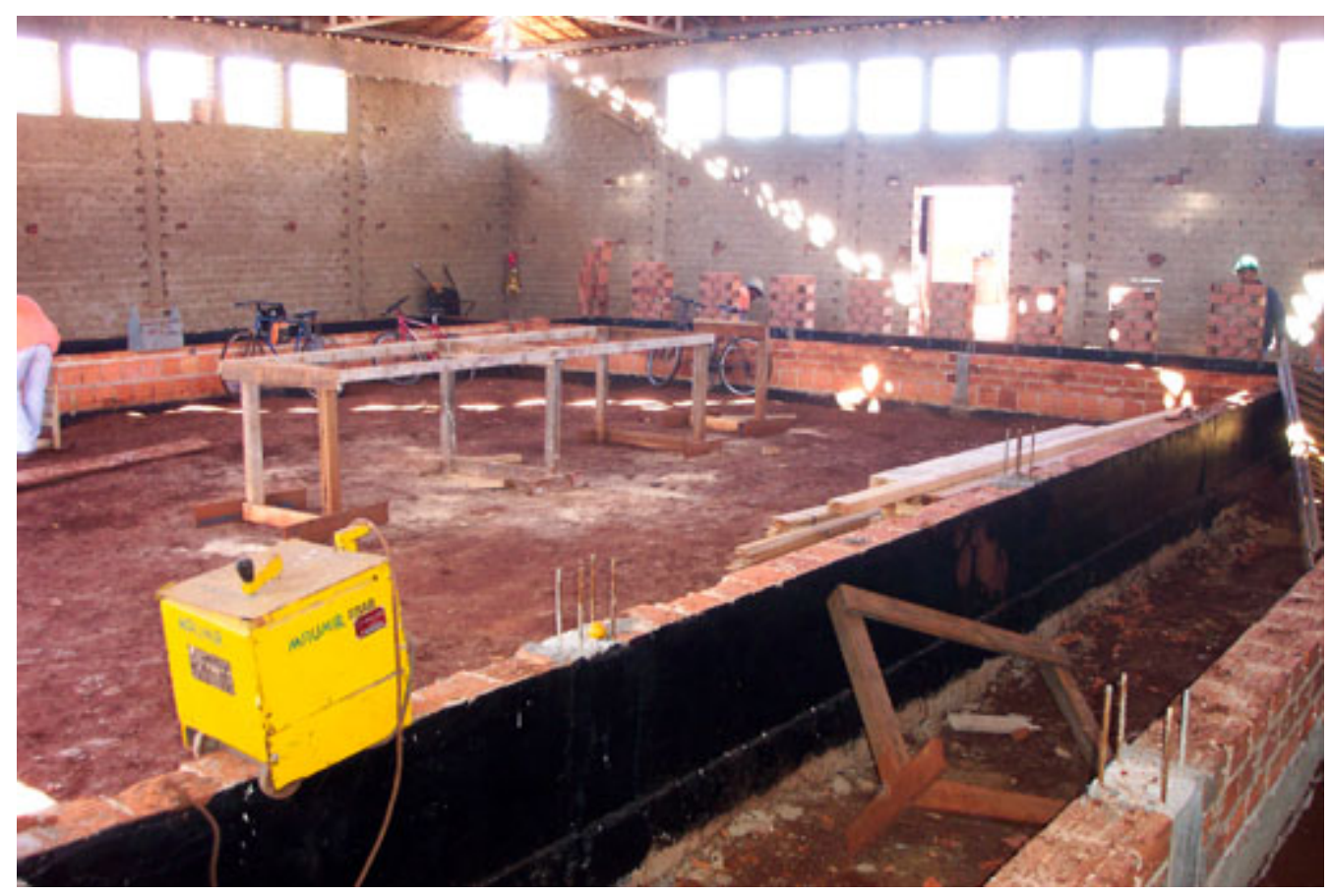


S. R. C. S. Barraviera. CEVAP - PRESENT, PAST AND FUTURE. J. Venom. Anim. Toxins incl. Trop. Dis., 2005, 11, 1, p. 2.

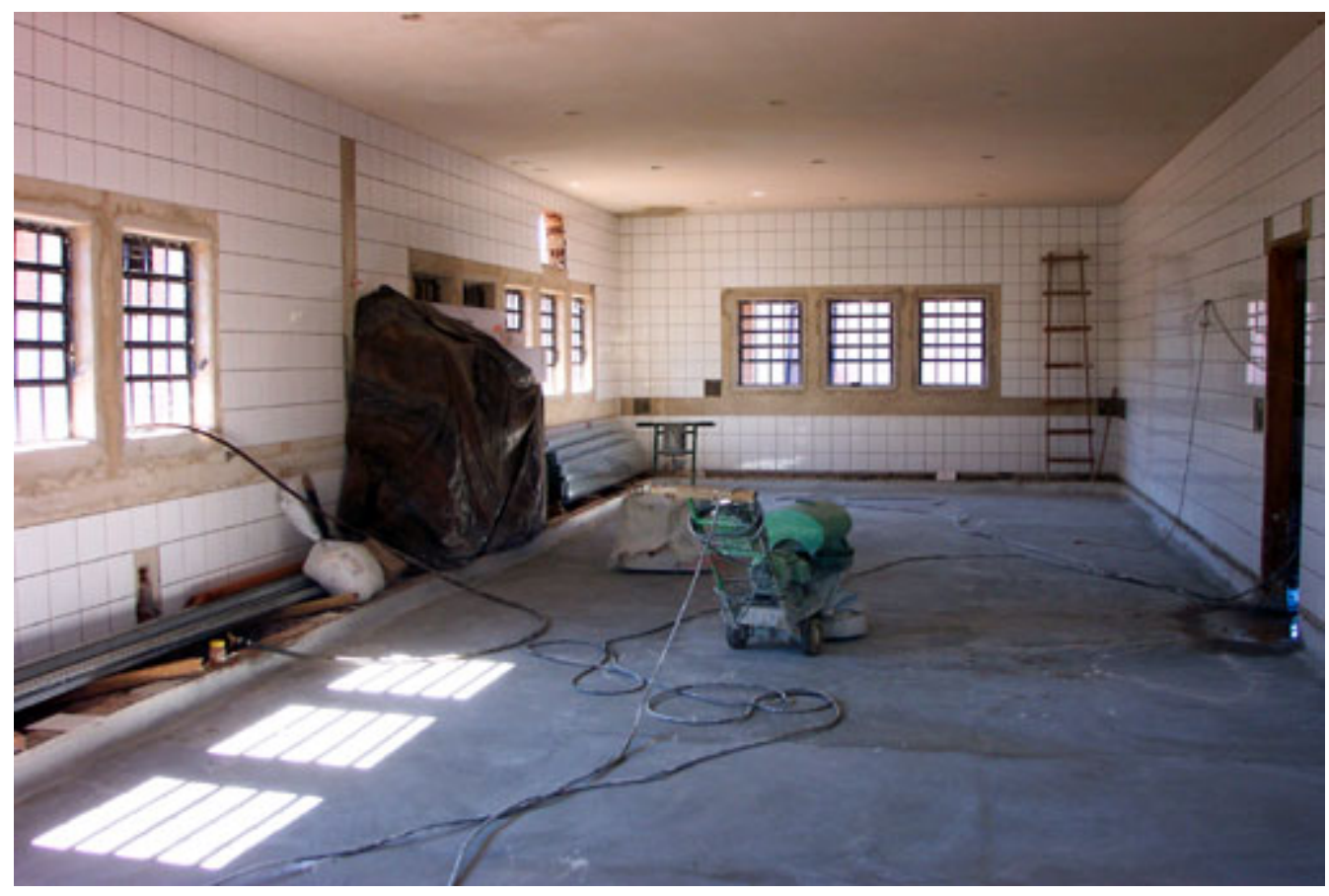


S. R. C. S. Barraviera. CEVAP - PRESENT, PAST AND FUTURE. J. Venom. Anim. Toxins incl. Trop. Dis., 2005, 11, 1, p. 2.

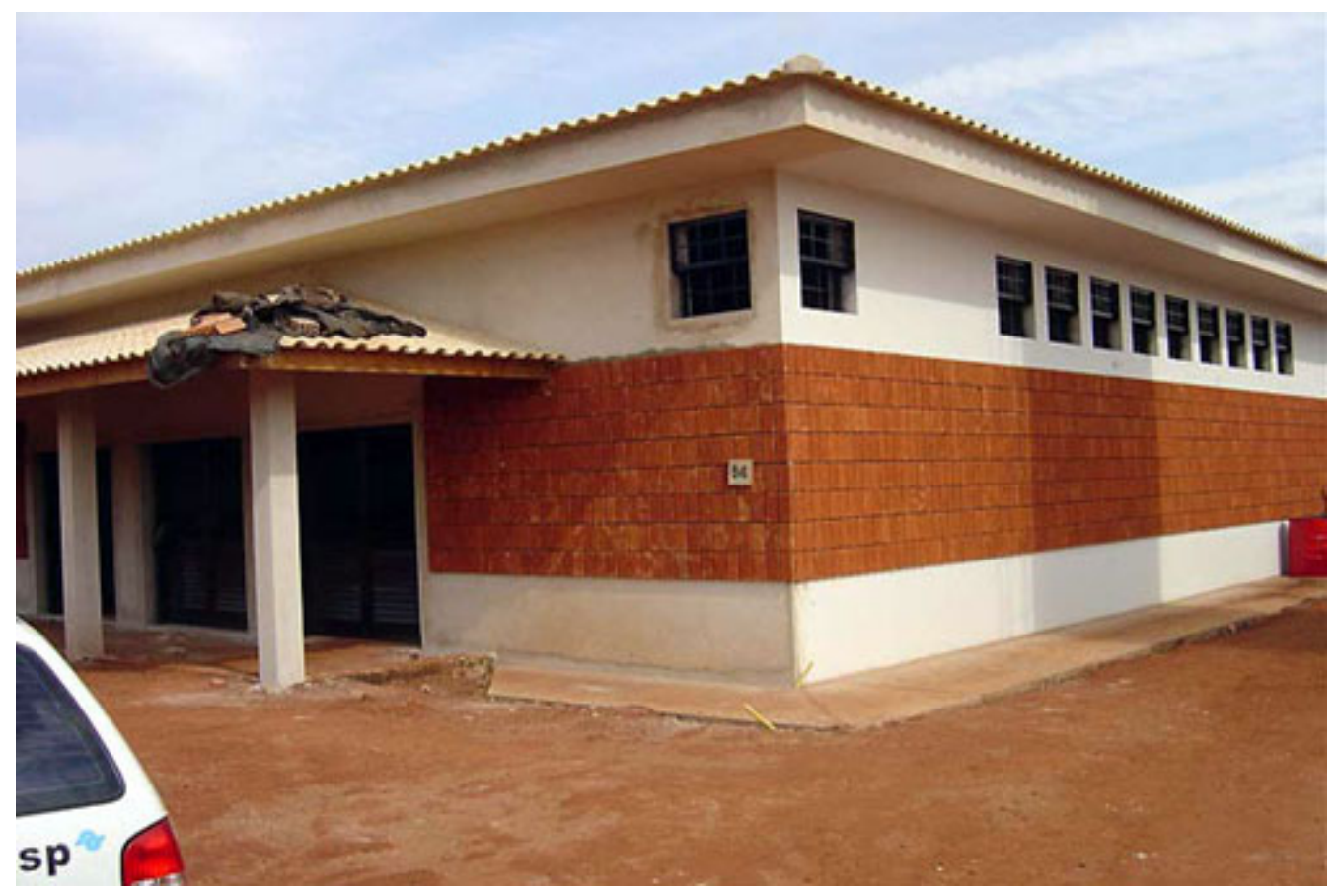


S. R. C. S. Barraviera. CEVAP - PRESENT, PAST AND FUTURE. J. Venom. Anim. Toxins incl. Trop. Dis., 2005, 11, 1, p. 2.

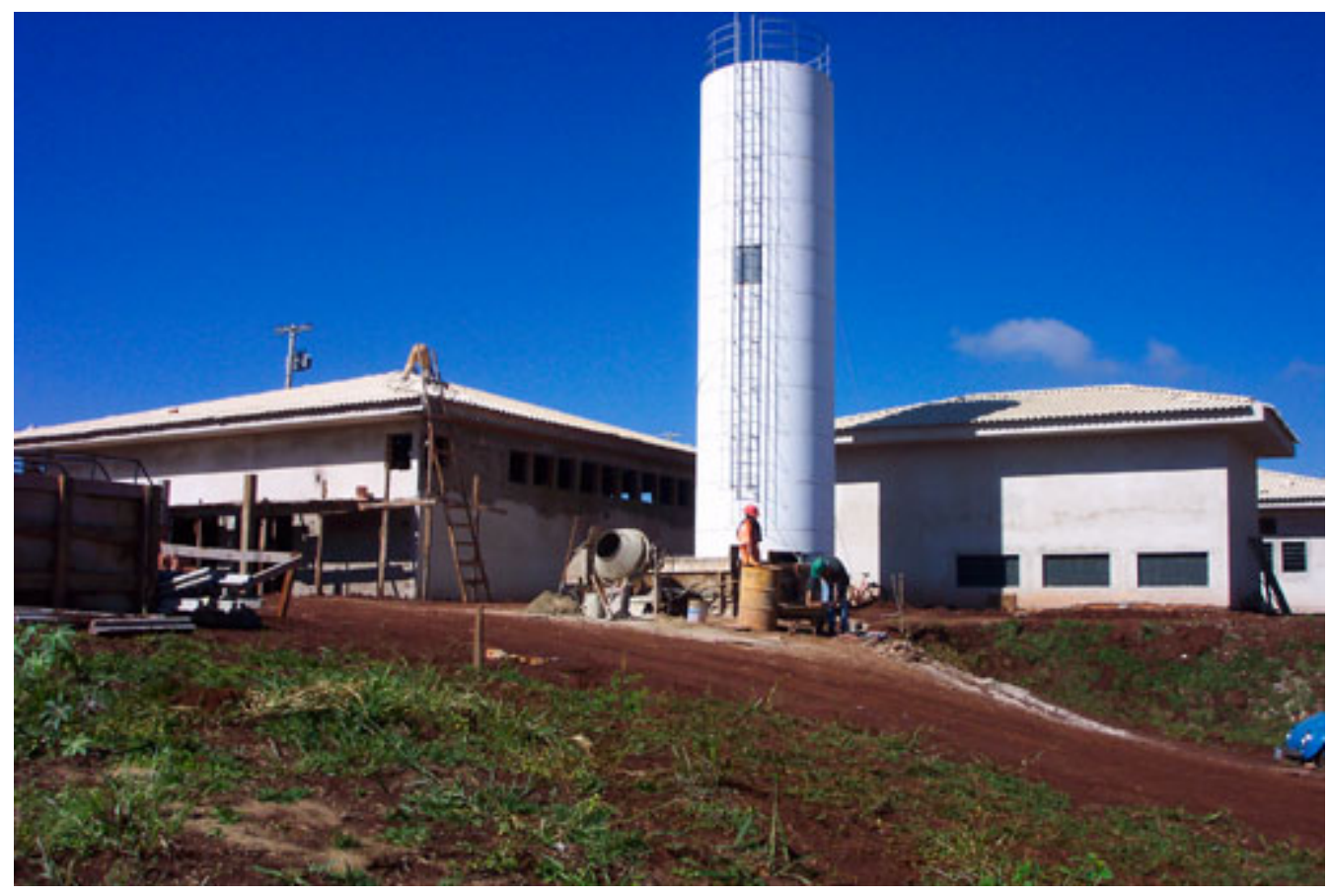


S. R. C. S. Barraviera. CEVAP - PRESENT, PAST AND FUTURE. J. Venom. Anim. Toxins incl. Trop. Dis., 2005, 11, 1, p. 2.

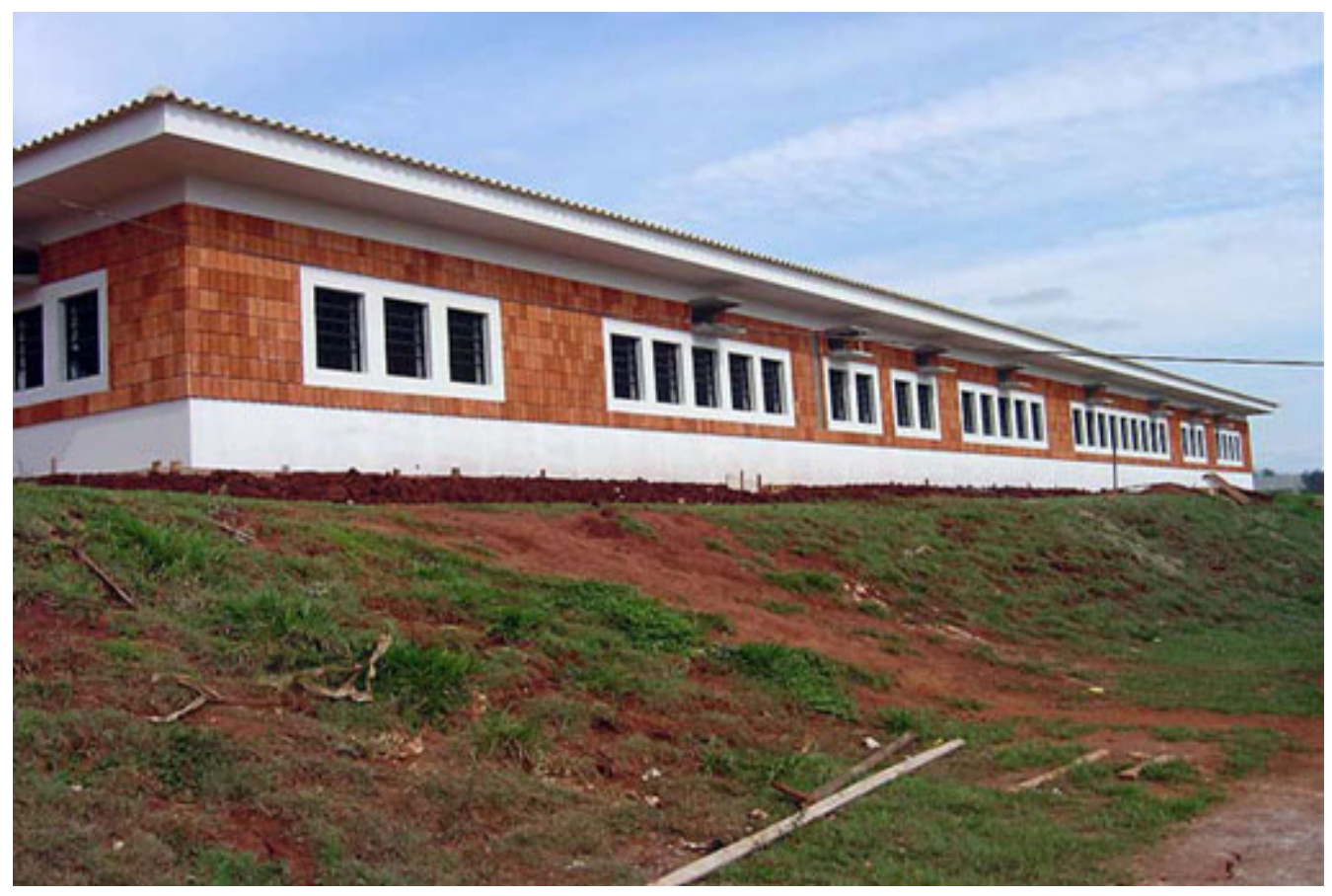


S. R. C. S. Barraviera. CEVAP - PRESENT, PAST AND FUTURE. J. Venom. Anim. Toxins incl. Trop. Dis., 2005, 11, 1, p. 2.

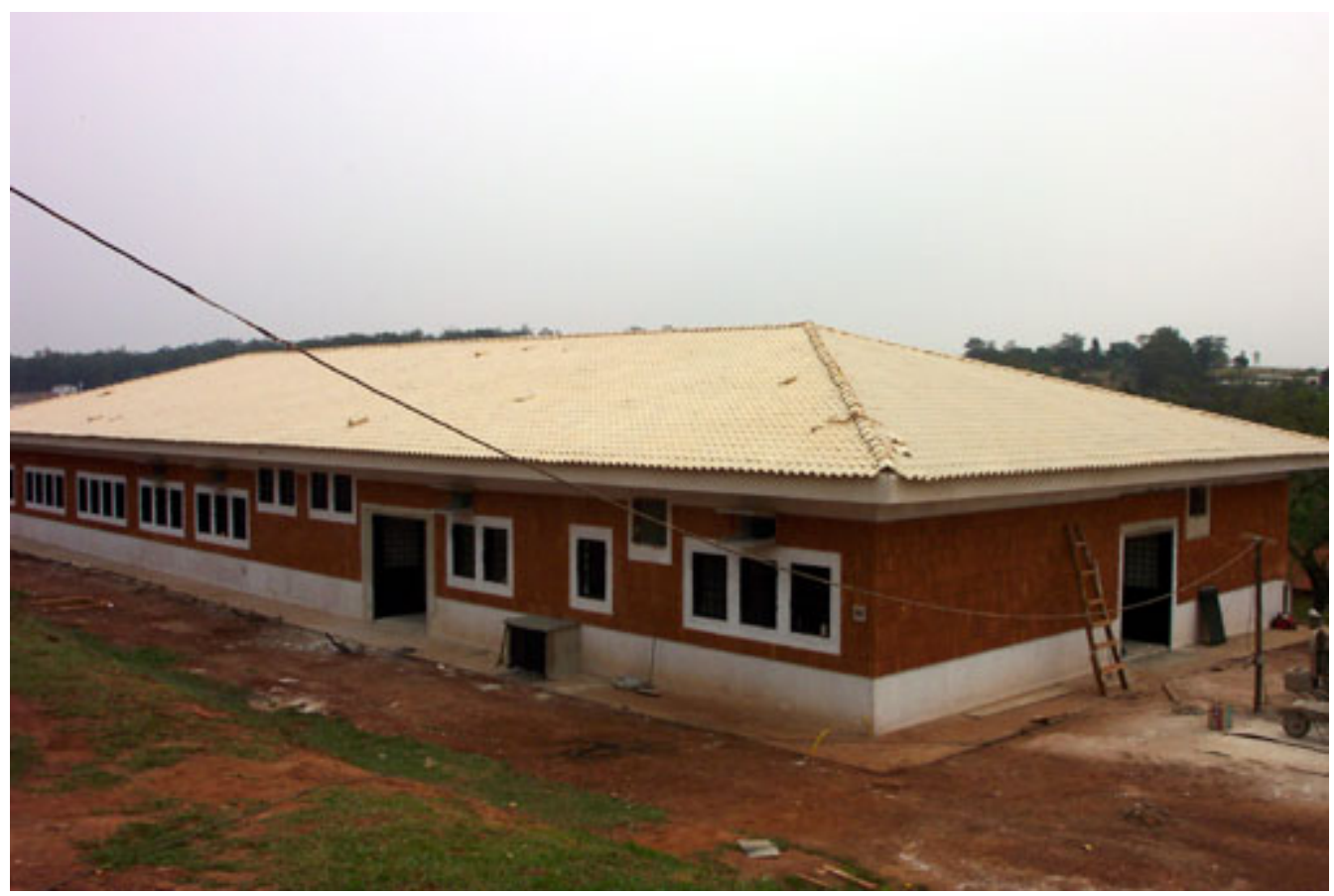

